\title{
Network in Nature Reserves of Fujian and Its Current Management
}

\author{
Miaoli Wu \\ Fuzhou University of International Studies and Trade \\ Fuzhou, China 350202
}

\begin{abstract}
On the basis of the collection of pertinent data and statistical processing of nature reserves in Fujian Province, this paper expounds the current situation of the construction and management of nature reserves in Fujian Province, and puts forward corresponding development countermeasures and measures for the main problems.
\end{abstract}

Keywords-Fujian; nature reserves; existing problems; countermeasures

\section{INTRODUCTION}

The enhancement of the construction and management of reserves is our government's undisguised commitment to the Convention on Biological Diversity and the Agenda 21 [1]. By the end of 2018 [2], China has established 2750 nature reserves of all kinds of types (excluding Hong Kong and Taiwan), with a total area of 1.47 million square kilometers, accounting for $14.8 \%$ of the total national territorial area. These nature reserves protect most of significant ecological systems and rare and endangered species in China. Their construction and development play a crucial role in protecting biodiversity, national ecological safety and promoting the construction of ecological civilization.

Fujian is located in the southeast coast region of China and the west coast of the Taiwan Strait. The coastline is 3752 $\mathrm{km}$ long, with numerous coastal harbors, islands and mud flats. The forest coverage rate has reached $66 \%$, ranking first in China. The vegetation forms are abundant, and the plant species are mainly subtropical flora. The vegetation in Fujian Province is divided into two parts by Mount Wuyi and Daiyun mountain running from northeast to southwest: the southern subtropical monsoon evergreen broad-leaved forest zone in the southeast coastal area (from the coastal herring bone in the east of Fujian to the inner mountain system of Jiufengshan mountain - Daiyun mountain - Bopingling Xianshan mountain) and the northwest mid-subtropical evergreen broad-leaved forest zone. Due to the complex topography, warm climate and abundant rainfall, there are significant differences in species composition and community surface structure in Fujian Province; consequently, it has special value in the protection of forest vegetation and marine organism. This paper intends to research the spatial distribution characteristics, problems and management status of nature reserves in Fujian Province, in order to provide basic support for the optimization of the network system of nature reserves in Fujian Province.

\section{NATURE RESERVE SYSTEM IN FUJIAN}

\section{A. Number, Type and Area}

Since the establishment of Wanmulin Nature Reserve, the first nature reserve in Fujian Province in 1957, after more than 60 years of construction, 92 nature reserves of all kinds of types have been built[2], with a total area of $4.45 \times 105$ $\mathrm{hm} 2$, of which 79 is terrestrial nature reserves, with an area of $4.08 \times 105 \mathrm{hm} 2$. The reserves are throughout the province, and the network in the nature reserves with relatively reasonable spatial arrangement and relatively complete types of protection has been basically formed.

According to the current classification standard of the Regulations of the People's Republic of China on Nature Reserves [3], Fujian has boasted 17 national nature reserves, with an area of $2.50 \times 105 \mathrm{hm} 2$, accounting for $13.04 \%$ and $40.73 \%$ of the total number and area of nature reserves in the province, respectively; 21 provincial-level nature reserves, with an area of $80227.68 \mathrm{hm} 2$, accounting for $27.17 \%$ and $27.54 \%$ of the total number and area of nature reserves in the province, respectively; 55 municipal and county-level nature reserves, with an area of $1.07 \times 105 \mathrm{hm} 2$, accounting for $59.78 \%$ and $31.73 \%$ of the total number and area of natural reserves in the province, respectively. The Mount Wuyi National Nature Reserve is a nature reserve with early establishment, larger area and very high value in China, which has joined the World Network of Biosphere Reserves in 1987.

According to the differences of protection objects, landscape natures and natural attributes [4], the 92 nature reserves in Fujian Province can be divided into 7 types, that is, forest ecosystem type, wild animals and plants type, inland wetland and aquatic ecosystem type, marine and coastal ecosystem type, and geological relic type (See "Table I"). It can be seen from the table that the overwhelming majority of nature reserves in Fujian Province are nature reserves of forest ecotype, and are dominated by the midsubtropical forest ecosystem type, while the nature reserves of coastal wetland type see slow development. In addition, there are a large number of nature reserves that belong to the polytype. For example, Tianbaoyan National Nature Reserve is not only a forest ecosystem protection type, but also an important protection area for wild animals and plants such as 
Tsuga longibracteata Cheng, rhododendron simiarum, sphagnum, etc.

TABLE I. TYPE Distribution OF NATURE RESERVE IN FUJIAN

\begin{tabular}{|l|l|l|l|l|}
\hline \multicolumn{1}{|c|}{ Category } & Type & Number & Area/hm2 & Area Proportion /\% \\
\hline Natural ecosystems & Forest ecosystem & 61 & 326577.40 & 53.23 \\
\hline & Inland wetland and aquatic ecosystem & 2 & 7030.00 & 31.80 \\
\hline & Marine and coastal ecosystem & 9 & 61417.04 & 0.84 \\
\hline Wildlife & Wild plants & 7 & 18711.47 & 13.47 \\
\hline & Wild animals & 9 & 24125.03 & \\
\hline Natural relics & Geological relic & 2 & 1360.00 & 0.66 \\
\hline & Ancient organism relics & 2 & 3300.00 & \\
\hline & Total & 92 & 445478.94 & 100.00 \\
\hline
\end{tabular}

\section{B. Regional Distribution}

It can be seen from "Table II" that Ningde City enjoys the largest number of established nature reserves (33), but the area of individual reserve is generally too small, and the smallest one is only $3 \mathrm{hm} 2$ (Kengdilou Reserve). There are few nature reserves in coastal cities such as Xiamen, Putian, Quanzhou, etc. Fuzhou, Putian and Ningde have not yet established national nature reserves, because most coastal areas, especially those located in the south subtropical zone, enjoy relatively developed local economy, and there is a large population with relatively little arable land. Due to the development of economy, the land is used in a large scale, and they have scruples or do not pay attention to the establishment of nature reserves, which limits the development of coastal nature reserves.

TABLE II. REgIONAL Distribution of NATURE RESERVES IN FuJIAN

\begin{tabular}{|l|l|l|l|l|}
\hline & Number of Reserve & Area of Reserve/Hm2 & Average Number of Reserve per & $\begin{array}{c}\text { Number of Counties with } \\
\text { County }\end{array}$ \\
\hline Total & 92 & 445478 & 1.35 & 50 \\
\hline Ningde & 33 & 83731 & 3.30 & 8 \\
\hline Fuzhou & 11 & 67135 & 1.22 & 7 \\
\hline Putian & 2 & 2848 & 1.00 & 1 \\
\hline Quanzhou & 5 & 27926 & 0.56 & 5 \\
\hline Xiamen & 1 & 33088 & 1.00 & 1 \\
\hline Zhangzhou & 15 & 27938 & 1.50 & 7 \\
\hline Longyan & 3 & 42301 & 0.43 & 3 \\
\hline Sanming & 10 & 62582 & 1.18 & \\
\hline Nanping & 12 & 97929 & 1.09 & 9 \\
\hline
\end{tabular}

In order to reflect the distribution characteristics of the reserves in the inter-city range, the geographic concentration index is adopted to study the concentration distribution degree of the reserves. The calculation formula [5] is as follows:

$$
\mathrm{C}=\sqrt{\sum_{\mathrm{i}=1}^{\mathrm{n}}\left(\frac{\mathrm{x}_{\mathrm{i}}}{\mathrm{T}}\right)^{2}} \times 100
$$

In the formula, $\mathrm{C}$ represents the geographic concentration index of reserves in Fujian Province; $\mathrm{n}$ is the total number of prefecture-level cities in Fujian Province; $\mathrm{Xi}$ is the number of reserves in the ith city; $\mathrm{T}$ is the total number of reserves in Fujian Province; and $\mathrm{Co}$ is the geographic concentration index of reserves averagely distributed in nine cities in Fujian Province. If $\mathrm{C}>\mathrm{Co}$, it means that the reserves are intensively distributed, otherwise, it means that the reserves are dispersedly distributed.

It can be seen from the calculation that the average number of reserves in nine cities of Fujian Province is 10.22, while the geographic concentration index of reserves is 45.05 . $\mathrm{C}$ is larger than $\mathrm{Co}$, which indicates that the distribution of the nature reserves in Fujian Province is relatively concentrated on the inter-city scale. In general, the construction of all kinds of nature reserves in Fujian has played a commendable role in protecting the middle and south subtropical evergreen broad-leaved forest, various migratory birds, beasts, reptiles, amphibians, shellfish, especially rare and endangered wild animals and plants, natural historical relics and other resources.

\section{Management System of the Reserves}

According to the principles and goals determined by the Outline of China Nature Reserve Development Plan (19962010), Fujian Province has compiled the Development Plan of Nature Reserves in Fujian Province, which provides the development direction and policy guarantee for the construction and management of the province's nature reserves. In 1995, Fujian Province has formulated the Regulations on the Management of Forest and Wildlife Type Nature Reserves in Fujian Province and has revised in 2017, with more strict restrictions on behaviors prohibited by laws and regulations. A series of regulations, notices and normative documents on the management of nature reserves within the jurisdiction have also been issued in succession. On this basis, the People's Congress of Fujian Province has passed the Measures for the Management of Nature Reserves in Fujian Province, which has improved the legal system of nature reserves in Fujian Province, improved the operability of relevant laws and regulations, and played a commendable 


\section{B. The Current Management System and Management Level Limit the Development of the Reserves}

There is room for further improvement in the effective management of nature reserves in Fujian Province. In terms of management objects, $15 \%-25 \%$ of the reserves fail to delimit the core area, buffer area and experimental area as required [9]. In terms of management actions, the relative shortage of professional and technical personnel in the administrative personnel leads to the failure of effective resource investigation, scientific research cooperation and dynamic monitoring in most nature reserves. Most nature reserves fail to well handle the relationship between the reserve management and the development and utilization of resources, which makes the main protection objects to face a huge threat. In terms of management mechanism, there are the following prominent problems in the nature reserves of our province:

- Multiple management, unclear rights and responsibilities. For example, Mount Wuyi National Nature Reserve is jointly managed by Fujian and Jiangxi Provinces;

- The establishment of rules and regulations for the management mechanism of nature reserves are not perfect;

- The management level of nature reserves is significantly different among different nature reserves:

- The management mode of the nature reserve is lack of connection with the surrounding social and economic environment, and is divorced from the reality. The conflict between the reserves and the local residents is frequent;

III. PROBLEMS EXISTED IN THE CONSTRUCTION AND MANAGEMENT OF NATURE RESERVES IN FUJIAN PROVINCE AND DEVELOPMENT COUNTERMEASURES

\section{A. The Networked Layout Is Not Obvious}

The cause of nature reserves in our province is still in the stage of continuous expansion and improvement. The number of nature reserves shows an overall increasing trend as evidenced by the number of nature reserves has increased from 68 in 2004 to 92 today. However, with the increase of the number of reserves, the area of reserves shows a downward trend as evidenced by the area of reserves has decreased from $473131.2 \mathrm{hm} 2$ in 2003 to $445478 \mathrm{hm} 2$. With the increased pressure of population and economic development, numerous rare or strategically important natural resources still need to be safeguarded through the establishment of certain reserves. For example, there are still 12 vacant species in reserves in our province, such as pelochelys bibroni, tire track eel, tiger frog, etc. [7]. In terms of the area of the reserves, they are mainly small and medium-sized island-type nature reserves, while the area of wetland type ecosystem is relatively small. It is suggested that several reserves with the same function should be formed into the reserve networks and habitat corridors [8] to promote the migration and exchange of regional species.
- "Nominal hierarchical management" between the management organization of the nature reserves and the local government results in the lack of administrative power of the nature reserves;

- The operation efficiency of management mechanism is low, and the mechanism of public participation and supervision is not perfect; meet the needs of the work of the reserves;

- The management of nature reserves has the problem of putting more emphasis on management than on operation;

- The application of classified management in the management of nature reserves is less;

- The management system of the whole nature reserve lacks effective coordination mechanism and relevant institutions.

In view of the above problems, a large number of scholars put forward the following solutions: first, rationalize the management system of the nature reserves, define the institutional positioning and management responsibilities; second, define the ownership of the nature reserves to make
- The expenditures related to the nature reserves cannot 
government investment, and establishing ecological compensation fund for nature reserves; secondly, it can properly develop ecological tourism, science popularization education, scientific research and other activities, and collect accommodation fee, catering fee and other license fees; thirdly, the fund can be solved by adopting wild animals and plants, holding special marketing and promotion activities, implementing natural protection membership system and attracting personal or social investment.

\section{CONCLUSION}

After many years of construction and management, the cause of nature reserves in Fujian Province has achieved remarkable results, which forms a natural reserve system with ecological service functions that takes the protection of the forest ecology in the middle and south subtropical zones, including various types of wild animals and plants, natural relics and marine coastal ecosystem, and the biological resources as its main tasks. However, due to the influence of social and economic factors, there are still many problems in the work of the reserves, especially in the protection objects and management mechanism, which need to strengthen the optimization of the reserve network in the future construction.

\section{REFERENCES}

[1] Compiled by the National Committee of the Chinese People and Biosphere. Nature Reserves and Ecotourism. Beijing: China Science and Technology Press, 1998 (in Chinese)

[2] Ministry of Ecological Environment of the People's Republic of China. China Nature Reserves in 2015 [EB/OL] (2016-11-08) [201910-06].

Http://www.mee.gov.cn/stbh/zrbhq/qgzrbhqm1/201611/p0201611255 59865886359.pdf (in Chinese)

[3] State Council of the People's Republic of China. Regulations of the People's Republic of China on Nature Reserves [J]. Bulletin of the State Council of the People's Republic of China, 1994 (24): 991-998 (in Chinese)

[4] Xue Dayuan, Jiang Mingkang. Study on the Classification Standard of Chinese Nature Reserves [J]. China Environmental Science, 1994, 14 (4): 246-250 (in Chinese)

[5] Kong Shi, Fu Liqiang, Song Hui, et al. Spatial Distribution Difference between China Nature Reserve and National Geological Park [J]. Journal of Northeast Agricultural University, 2014 (9): 73-78 (in Chinese)

[6] Chen Chuanming. Investigation on the Current Situation of Nature Reserves in Fujian Province and Development Countermeasures [J]. Forestry Construction, 2005 (6): 40-42 (in Chinese)

[7] Tan Yong, He Dongjin, You Weibin, et al. GAP Analysis of Biodiversity Conservation of Nature Reserve in Fujian Province [J]. Journal of Fujian Agriculture and Forestry University (Natural Edition), 2014, 43 (3): 251-255 (in Chinese)

[8] Gu Fan, Huang Yixiong, Chen Chuanming, et al. Construction and Optimization of Ecological Network of Nature Reserve in Fujian Province [J]. Journal of Applied Ecology, 2017 (3): 1013-1020 (in Chinese)

[9] Tang Qiaoqian, Jiang Xitian. Evaluation on the Effectiveness of the Management of Nature Reserves - Fujian Province as an Example [J] Journal of Putian University, 2016, 23 (5): 37-42 (in Chinese)

[10] Tian Shuxin, Zou Limei. Countermeasures on Improvement of the Capital Investment Mechanism of China's Nature Reserves [J]. China Forest By-product and Speciality, 2006, (2): 82-85 (in Chinese) broaden the channels of fund investment, including attracting foreign investment and social donation on the basis of 